\title{
Bleeding abdominal scar endometriosis-a case report
}

\author{
Badal Das*, Malay Sarkar, Debobroto Roy, Krishna Pada Das, \\ Nazmin Khatun, Aritrick Moulick
}

Department of Obstetrics and Gynecology, Burdwan Medical College and Hospital, Burdwan, West Bengal, India

Received: 30 May 2021

Accepted: 30 June 2021

\author{
*Correspondence: \\ Dr. Badal Das, \\ E-mail: drbd.sskm@gmail.com
}

Copyright: (c) the author(s), publisher and licensee Medip Academy. This is an open-access article distributed under the terms of the Creative Commons Attribution Non-Commercial License, which permits unrestricted non-commercial use, distribution, and reproduction in any medium, provided the original work is properly cited.

\begin{abstract}
Presence of functional endometrial tissue anywhere outside the uterine mucosa is called endometriosis. It is hormone dependent and almost exclusively it affects the women of reproductive age. Abdominal scar endometriosis is a rare condition and it is due to deposition of endometriotic tissue in the wound site during various obstetric or gynecological operative procedures. Scar endometriosis followed by lower segment caesarean section (LSCS) is very rare and presents with co-menstrual pain and bleeding. Our case presented with active bleeding from abdominal LSCS scar during menstruation which is extremely a rare presentation. Wide excision and histo-pathological examination confirm the diagnosis. A 28-year-old lady with previous history of LSCS 2 years back presented with complaining of swelling and bleeding from the previous LSCS scar during menstruation, persisting for 4-5 days, repeatedly in every menstrual cycle for last 6 months. On examination a swelling with active bleeding from it was noted over the previous LSCS scar. Routine investigation and coagulation profile was with in normal limit and on ultrasonography a firm mass was noted. After wide excision and histo-pathological Examination, the diagnosis was confirmed. Co-menstrual swelling, pain and bleeding from the previous LSCS scar should not be neglected and may be due to scar endometriosis.
\end{abstract}

Keywords: Scar Endometriosis, LSCS, Endometriotic tissue, Histo-pathological, Rectus abdominis, Hysterotomy

\section{INTRODUCTION}

Presence of functional endometrial tissue outside the uterine cavity is defined as endometriosis. ${ }^{1,2}$ Common sites of involvement are the ovaries, pelvic peritoneum, deep pelvic sub-peritoneal spaces, the intestinal system, and the urinary system in decreasing order of frequency. ${ }^{1}$ Abdominal scar endometriosis after caesarean section is a very rare type of endometriosis with incidence of $0.03 \%$ $0.4 \%$ which is difficult to diagnose. ${ }^{3,4}$ Surgical excision and histopathology of the lesion is the only confirmatory option of diagnosis. Few Cases of endometriosis of the abdominal scar following various obstetrical and gynecological surgical procedures have been reported with different types of clinical presentations. ${ }^{2-4}$ But abdominal scar endometriosis with active bleeding is a very rare form of presentation.
We report a case of endometriosis of lower abdominal scar of previous caesarean section with active bleeding from it.

\section{CASE REPORT}

A 28-year-old lady with previous history of LSCS 2 years back presented with complaining of swelling and bleeding from the right side of previous LSCS scar during menstruation, persisting for 4-5 days, repeatedly in every menstrual cycle for last 6 months (Figure 1). On examination patient was vitally stable and respiratory, cardiovascular and gastrointestinal system was with in normal limit. There was a $5 \times 3 \mathrm{~cm}^{2}$ swelling with mild ulceration in the right side of the previous LSCS scar which was firm in consistency, severely tender and fixed with anterior abdominal wall (Figure 2). Her menstruation was ongoing and there was active bleeding from the swelling. Her routine blood investigations and coagulation 
profile were within normal limit. An ultrasonography was performed which revealed a $61 \times 41 \mathrm{~mm}^{2}$ hyper-echoic complex mass involving the sub-cutaneous tissue and rectus muscle. Provisional diagnosis was made as scar endometriosis. Wide dissection and meticulous excision were done under spinal anaesthesia and the specimen was sent for histopathological examination preserving in $10 \%$ formalin solution. The post-operative period was uneventful. The histo-pathological findings were presence of endometrial gland, stromal cells and hemosiderin laden macrophages and so the diagnosis was confirmed as scar endometriosis.

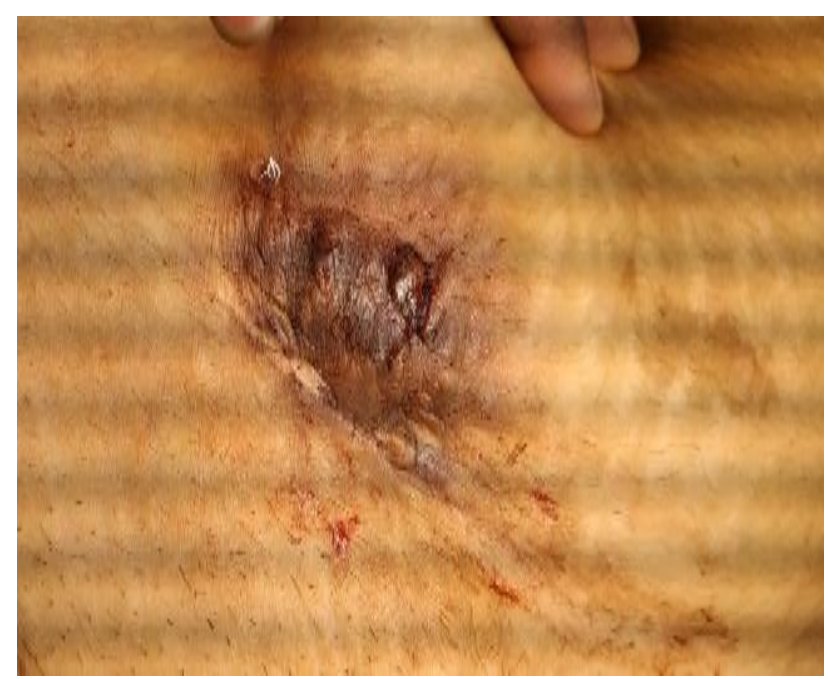

Figure 1: Bleeding from scar endometriosis.

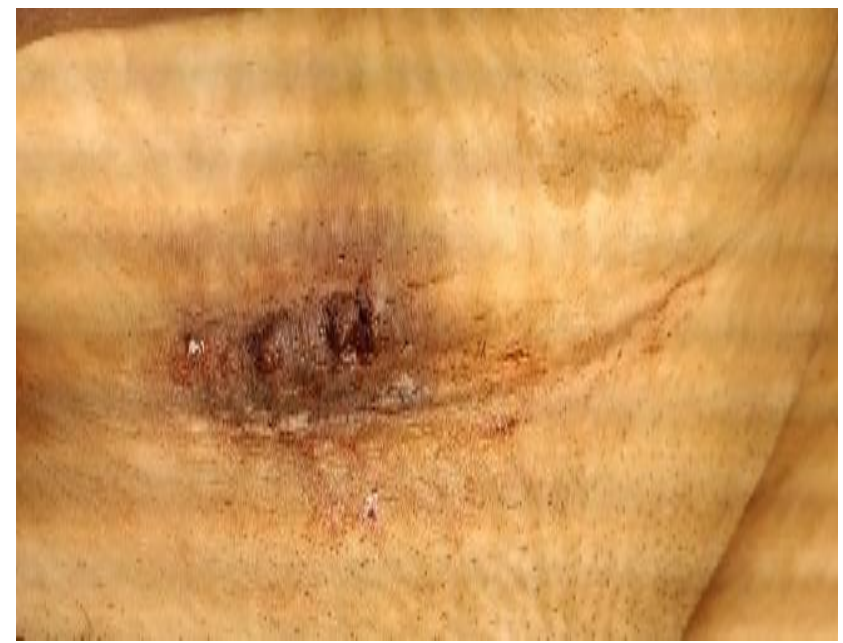

Figure 2: Abdominal LSCS scar endometriosis.

\section{DISCUSSION}

Endometriosis is a benign gynecological condition with aggressive features. It is estimated to occur in $10 \%$ of the female population. It is almost exclusively a disease of women in their reproductive age group. ${ }^{5}$ As these endometriotic lesions are hormone dependent, they have tendency to bleed with each menstrual cycle. So, the lesions are becoming more congested and larger in size gradually. And the patients are feeling cyclical pain and discomfort. ${ }^{6}$ Common sites of involvement are the ovaries, pelvic peritoneum, deep pelvic sub-peritoneal spaces, the intestinal system, and the urinary system in decreasing order of frequency. ${ }^{1}$ Scar endometriosis is a very rare disease entity., In case of abdominal wall scar endometriosis, the endometriotic tissue is deposited in the dermal and subcutaneous tissue, the rectus abdominis muscle and the rectus sheath. ${ }^{2}$ Following hysterotomy, the reported incidence of abdominal scar endometriosis is $1.08-2 \%$, whereas the incidence is $0.03-0.4 \%$ after caesarean section. ${ }^{2-4}$ The implantation of decidual cells during various surgical procedures has been attributed to be the etiology of scar endometriosis. These decidual cells subsequently proliferate or induce metaplasia in the surrounding cells. This pathogenic process is influenced by estrogen. That is why endometriosis is a disease of reproductive age group.

In our case, it is attributed that decidual cells were inoculated in the dermal, subcutaneous tissue and in rectus abdominis muscle during previous caesarean section which were subsequently proliferated gradually under the influence of estrogen. During menstruation under hormonal effect bleeding starts from this endometriotic tissue which is revealed by making a rent in the overlying skin. This type of visible active bleeding from previous caesarean scar endometriosis during menstruation is a very rare condition.

\section{CONCLUSION}

Active bleeding from abdominal scar during menstruation may be a clinical presentation of scar endometriosis. Wide excision and histopathological examination are confirmatory to the diagnosis.

\section{ACKNOWLEDGMENTS}

Authors are thankful to the anesthetist, OT nursing staffs, OT technicians and all of their colleagues for immense cooperation.

\section{Funding: No funding sources \\ Conflict of interest: None declared \\ Ethical approval: Not required}

\section{REFERENCES}

1. Bazot M, Darai E, Hourani R, Thomassin I, Cortez A, Uzan $\mathrm{S}$ et al. Deep pelvic endometriosis: MR imaging for diagnosis and prediction of extension of disease. Radiology. 2004;232:379-89.

2. Kafkasli A, Franklin RR, Sauls D. Endometriosis in the uterine wall cesarean section scar. Gynecol Obstet Invest. 1996;42:211-3.

3. Taff L, Jones S. Cesarean scar endometriosis: A report of two cases. J Reprod Med. 2002;47:50-2. 
4. Goel P, Sood SS, Dalal A, Romilla Cesarean scar endometriosis: Report of two cases. Indian J Med Sci. 2005;59:495-8.

5. Kataoka ML, Togashi K, Yamaoka T, Koyama T, Ueda H, Kobayashi $\mathrm{H}$ et al. Posterior cul-de-sac obliteration associated with endometriosis: MR imaging evaluation. Radiology. 2005;234:815-23.

6. Kinkel K, Frei KA, Balleyguier C, Chapron C. Diagnosis of endometriosis with imaging: A review. Eur Radiol. 2006;16:285-98.

7. Balleyguier C, Chapron C, Chopin N, Helenon O, Menu Y. Abdominal wall and surgical scar endometriosis: Result of magnetic resonance imaging. Gynecol Obstet Invest. 2003;55:220-4.
8. Tafazoli F, Reinhold C. Uterine adenomyosis: Current concepts in imaging. Semin Ultrasound CT MR. 1999;20:267-77.

9. Lahiri AK, Sharma K, Ashim K, Busiri N. Endometriosis of the uterine cesarean section scar-A case report. Indian J Radiol Imaging. 2008;18(1):668 .

Cite this article as: Das B, Sarkar M, Roy D, Das KP, Khatun N, Moulick A. Bleeding abdominal scar endometriosis: a case report. Int J Reprod Contracept Obstet Gynecol 2021;10:3239-41. 